\title{
Exercício físico e sistema imunológico: mecanismos e integrações
}

\author{
Carol Leandro ${ }^{1}$ \\ Elizabeth do Nascimento ${ }^{2}$ \\ Raul Manhães-de-Castro ${ }^{2}$ \\ José Alberto Duarte ${ }^{1}$ \\ Célia M.M.B. de-Castro ${ }^{3}$
}

\author{
${ }^{1}$ Laboratório de Bioquímica e Morfologia Experimental \\ Faculdade de Ciências do Desporto e de Educação Física \\ Universidade do Porto, Portugal \\ ${ }^{2}$ Laboratório de Fisiologia da Nutrição Naíde Teodósio \\ Departamento de Nutrição, Centro de Ciências da Saúde (CCS) \\ Universidade Federal de Pernambuco (UFPE), Brasil \\ ${ }^{3}$ Laboratório de Imunopatologia Keizo Asami (LIKA) \\ Departamento de Medicina Tropical, CCS, UFPE, Brasil
}

ABSTRACT

RESUMO

O exercício físico induz alterações transitórias no sistema imunológico. A intensidade, a duração e o tipo de exercício determinam as alterações ocorridas durante e após esforço. Na resposta aguda ao exercício, os sistemas imunológico e neuroendócrino interagem através de sinais moleculares na forma de hormonas, citocinas e neurotransmissores. Constata-se a existência de um verdadeiro sistema de inter e intra-comunicação que participa, como um todo, na coordenação, integração e regulação dos eventos durante o esforço físico. Neste artigo, são relatados estudos evidenciando a influência dos diferentes tipos de exercício físico sobre a concentração e a função de componentes do sistema imunológico. Serão ainda discutidos pontos relevantes da integração entre o sistema nervoso, o sistema endócrino e em particular o sistema imunológico durante o exercício físico.

Palavras-chave: Exercício físico; resposta imune; sistema nervoso; sistema endócrino; sistema imunológico.
Physical exercise and immune system: mechanisms and integration processes

Physical exercise induces temporary changes on the immune system. Exercise-induced changes in the immune system are dependent on the intensity, duration and type of physical exercise. In the acute phase response to physical exercise, the neuroendocrine and the immune systems interact through molecular signals in the form of cytokines, hormones, and neurotransmitters. Indeed, there is a system of intra and intercommunication that participates as a whole in the coordination, integration, and regulation of the body during physical effort. In this review, we will discuss some earlier studies which described the influences of different kinds of physical exercise on the concentration and the function of the components of the immune system. Furthermore, we will discuss important points of the interaction between the neuroendocrine and the immune systems during and after exercise.

Keywords: Physical exercise; immune response; nervous system; endocrine system; immune system. 


\section{INTRODUÇÃO}

Já está bem definido que o exercício físico (EF), enquanto modelo mensurável de indução de stress, provoca alterações funcionais no sistema imunológiCo (SI) $7,32,35,74,80$.

Diferentes tipos e cargas de EF podem provocar alterações distintas nos parâmetros imunes ${ }^{35}$. Alguns estudos vêm demonstrando que o EF moderado $\left(<60 \%\right.$ do $\left.\mathrm{VO}_{2 \text { máx }}\right)$ parece estar relacionado ao aumento da resposta dos mecanismos de defesa orgânica9,13,57,85,89,59, enquanto que o EF mais intenso e prolongado ( $>65 \%$ do $\mathrm{VO}_{2 \max }$ ) ou o treino excessivo parecem enfraquecê-la ${ }^{13,22,29,43,56}$.

$\mathrm{Na}$ base desta influência poderá estar a inter-relação existente entre o sistema nervoso (SN), o sistema endócrino (SE) e o $\mathrm{SI}^{5}$. De fato, durante a actividade física ocorre activação inicial do sistema nervoso simpático (SNS), que estimula a produção e a libertação de catecolaminas, hormonas e neurotransmissores relacionados ao stress ${ }^{32}$. Além disso, há também activação do eixo hipotálamo-pituitária-adrenal (HPA) que parece possuir uma relação intrínseca com as componentes do SI, não só pela presença de receptores hormonais em leucócitos, mas também pela relação anatómica observada entre os três sistemas 26,32 . Esta revisão tem por objectivo abordar os pontos relevantes da influência dos diferentes tipos de EF sobre a concentração e a funcionalidade de algumas componentes do SI. Para uma compreensão mais abrangente, serão relatados também estudos evidenciando a integração entre o SN, o SE e, em particular, o SI, observados durante o EF.

\section{EXERCícIO FÍSICO E A IMUNIDADE}

Diferentes tipos e cargas de EF podem provocar alterações distintas no $\mathrm{SI}^{35}$. Neste sentido, é importante conhecer como o exercício agudo (carga súbita de $\mathrm{EF}$ ), moderado (entre 50 a $65 \%$ do $\mathrm{VO}_{2 \text { máx }}$ ) ou intenso (acima de $65 \%$ do $\mathrm{VO}_{2 \text { máx }}$ ) podem influenciar alguns parâmetros da imunidade tanto celular como humoral13,35.

Um estudo pioneiro nessa área foi realizado no início do século XX (1902) por Larrabee (para refs. ver ${ }^{57}$ ), o qual verificou uma leucocitose em corredores a seguir uma maratona, decorrente, sobretudo, do aumento do número de neutrófilos na circulação. Contudo, a relação entre EF e SI tornou-se mais sóli- da a partir de observações realizadas por pesquisadores acerca do aumento da incidência de infecções do trato respiratório superior (IRTS) em atletas após treinamentos intensos ou prolongados, e/ou competições exaustivas $29,42,56,77,80$. Os efeitos do EF sobre as componentes do SI são empiricamente conhecidos, apesar de só recentemente estarem a ser estudados os mecanismos subjacentes a estas influências.

De forma geral, o EF agudo provoca um aumento na concentração de leucócitos na circulação ${ }^{45}$. A leucocitose observada durante e após o exercício decorre principalmente do aumento da concentração de neutrófilos ${ }^{35,45}$. Este aumento parece resultar da migração de células do tecido endotelial para o sangue ou como parte da resposta inflamatória às lesões no tecido muscular $70,45,84$.

Os neutrófilos polimorfonucleares (PMN) compreendem a sub-população de leucócitos de maior número na circulação ${ }^{35}$. Para desempenhar suas funções nos tecidos, os PMN migram na direção de partículas a serem ingeridas (quimiotaxia) ${ }^{78}$. Daí então podem reconhecer, aderir e engolfar muitos micróbios, bactérias e vírus (fagocitose) e descarregar o conteúdo de seus grânulos citoplasmáticos nos vacúolos fagocíticos (desgranulação) ${ }^{78}$. Para além disso, os PMN são mediadores da lesão tecidual durante a inflamação, via libertação de espécies reactivas de oxigênio e outros factores tóxicos (actividade oxidativa) ${ }^{79}$.

Os estudos sobre o efeito do EF moderado na função de PMN ainda são conflitantes. Muitos pesquisadores verificaram que o EF moderado parece auxiliar a quimiotaxia, a desgranulação e a actividade oxidativa dos PMN a seguir 1 hora de EF a $60 \%$ $\mathrm{VO}_{2 \text { máx }} 39,50,60,83,85$. Entretanto, Pyne et al ${ }^{79}$ encontraram uma diminuição na actividade oxidativa de PMN em atletas a seguir 40 minutos de EF aeróbico a $65 \%$ do $\mathrm{VO}_{2 \text { máx }}$. Um estudo verificou um aumento na actividade oxidativa de PMN tanto em atletas quanto em sujeitos não-treinados antes e a seguir 1 hora de EF aeróbico a $60 \%$ do $\mathrm{VO}_{2 \text { máx }}{ }^{83}$. Muns et al ${ }^{49}$ verificaram um aumento da actividade fagocítica dos PMN em homens treinados 24 horas a seguir uma corrida de $20 \mathrm{~km}$ a $60 \%$ do $\mathrm{VO}_{2 \text { máx }}$. Por outro lado, Ortega et al ${ }^{160}$ não encontraram alteração significativa na actividade fagocítica de PMN imediatamente a seguir 1 hora de bicicleta a $50 \%$ do $\mathrm{VO}_{2 \text { máx }}$ em 
homens sedentários. A variabilidade do tempo de avaliação da função destas células a seguir o EF, o nível de aptidão física individual e os diferentes protocolos experimentais utilizados podem justificar os diversos resultados encontrados.

Contrariamente ao EF moderado, os estudos referentes à resposta funcional de PMN ao EF intenso parecem mais consistentes. Com excepção da actividade fagocítica e da desgranulação, as funções dos PMN parecem diminuir a seguir um EF intenso86,102. Alguns estudos verificaram que a capacidade oxidativa destas células é temporariamente atenuada durante uma carga aguda de EF intenso ( $>85 \%$ do $\left.\mathrm{VO}_{2 \text { máx }}\right)$ e no período de recuperação $28,78,81,83$. Pedersen e Bruunsgaard 72 relatam que a imunossupressão observada é apenas evidente quando o EF é intenso e de longa duração (60 min ou mais).

Robson et al ${ }^{82}$ compararam o efeito de um EF a $80 \%$ $\mathrm{VO}_{2 \text { máx }}$ (durante 1 hora) com um $\mathrm{EF}$ a $55 \% \mathrm{VO}_{2 \text { máx }}$ (durante 3 horas) em indivíduos activos. Estes autores verificaram, contudo, que durante e a seguir o esforço houve um aumento similar na contagem de PMN nas duas intensidades ${ }^{82}$. Curiosamente, a diminuição da actividade oxidativa e anti-bactericida destas células foi mais pronunciada a seguir o EF moderado $^{82}$. Assim, as alterações nas funções dos neutrófilos parecem ser dependentes não somente da intensidade, mas também da duração do esforço. Aliás, as alterações funcionais destas células em reposta a diferentes cargas de EF podem ser clinicamente significativas refletindo um estado de stress ou imunossupressão associados ao EF, assim como um indicativo de overtraining.

Outra linhagem de células fagocíticas inclui os mononucleados: monócitos e macrófagos ${ }^{102}$. Os monócitos são células disponíveis no sangue periférico que continuamente se diferenciam em macrófagos após migrarem para os tecidos ${ }^{102}$. Os macrófagos estão presentes em vários tecidos, órgãos e cavidades ${ }^{101}$. O EF agudo, independente da intensidade e da duração, parece provocar uma monocitose temporária ${ }^{21}$. Por outro lado, a quantificação de macrófagos nos tecidos em resposta a um EF é relativamente inacessível em humanos ${ }^{21}$.

Os fagócitos mononucleares são importantes células efectoras, altamente regulados por outras células (linfócitos T e B) e por mediadores químicos produ- zidos pelo SNS e pelo eixo HPA ${ }^{101}$. Estão envolvidos na fagocitose e na actividade microbicida e antitumoral, manifestam uma função celular acessória como apresentadores de antigénio e promovem o desenvolvimento da imunidade mediada por linfócito100,102. São também uma fonte de citocinas mediadoras das reacções inflamatórias e fisiopatológicas que acompanham a lesão celular102. Aspectos característicos dos macrófagos incluem a capacidade de aderência, a quimiotaxia, a produção de anião superóxido e a citotoxicidade ${ }^{17,103}$. Estas células também possuem a capacidade de manifestar efeitos pró e antiinflamatórios sobre a função de outros tipos celulares ${ }^{103}$.

O stress provocado pelo EF parece ter um efeito estimulador na função de macrófagos ${ }^{101}$. Tanto o EF moderado como o intenso podem aumentar várias funções destas células incluindo a quimiotaxia, a aderência, a produção de anião superóxido, a taxa de metabolismo do nitrogénio, a actividade citotóxica e a capacidade fagocítica $21,53,62,98,99,102$. Os mecanismos subjacentes a estas respostas ainda permanecem desconhecidos, mas podem estar associados a factores neuroendócrinos $23,60,63,75,101$. Ademais, ainda são necessários estudos que investiguem a significância fisiológica das alterações funcionais destas células. Em animais, Woods et al ${ }^{99}$ observaram que tanto uma corrida exaustiva num tapete $(18-35 \mathrm{~m} / \mathrm{min}$, $5 \%$ de inclinação, durante $2-4 \mathrm{~h}$ ) quanto uma moderada $(18 \mathrm{~m} / \mathrm{min}, 5 \%$ de inclinação, durante $30 \mathrm{~min})$ podem provocar um aumento da citotoxicidade antitumoral de macrófagos peritoniais. Outro estudo observou um aumento no processo fagocítico de macrófagos peritoneais de ratos submetidos à natação até a exaustão ou submetidos ao treino (90 minutos de nado durante 20 dias) ${ }^{20}$. Entretanto, Davis et al ${ }^{15}$ verificaram recentemente que um EF extenuante de longa duração $(2.5-3.5 \mathrm{~h})$ pode provocar diminuição na actividade anti-viral de macrófagos alveolares e aumentar a susceptibilidade de infecções em ratos. Woods et al ${ }^{100}$ também verificaram que o EF muito intenso e de curta duração induziu a uma redução na capacidade de apresentação de antigénios por macrófagos peritoneais em camundongos. De forma geral, o EF provoca alterações nestas células, contudo o efeito modulador parece depender do parâmetro a ser avaliado, da 
intensidade, do tipo e mais pronunciadamente da duração do exercício. Todavia, a localização tecidual específica do macrófago estudado parece ser mais determinante.

Nos tecidos também são encontradas outros tipos de células do $\mathrm{SI}^{36}$. Os linfócitos teciduais estão em equilíbrio dinâmico com aqueles do sangue e recirculam continuamente através de canais vasculares e linfáticos, de um órgão linfóide para o outro ${ }^{36}$. O aumento da concentração destas células durante o EF agudo, moderado ou intenso, decorre do recrutamento de todas as suas populações (células natural killer (NK), linfócitos T e linfócitos B) para o compartimento vascular, constituindo uma resposta altamente estereotipada ${ }^{70,76}$. Portanto, durante o exercício, é verificado um aumento de linfócitos em cerca de $50 \%$ a $100 \%$ em relação ao valor basal 76 . No período de recuperação (30 minutos após o exercício), a contagem de linfócitos diminui de $30 \%$ a $50 \%$ abaixo dos níveis pré-exercício, permanecendo assim durante 3 a 6 horas ${ }^{76}$.

Dentre as populações de linfócitos, as células NK parecem ser as mais responsivas imediatamente a seguir uma carga súbita de EF97. As células NK são conhecidas por desencadearem defesa precoce contra certas infecções intracelulares ${ }^{97}$. Deste modo, elas participam da exterminação de células tumorais e células infectadas por vírus (actividade citolítica), sem necessidade prévia de imunização ou activação $0^{97}$.

Exercícios de vários tipos, durações e intensidades induzem o recrutamento de células NK para o sangue, assim como provocam alterações na actividade citolítica destas células 37,73 . Tvede et al93 estudaram a resposta das populações de linfócitos em ciclistas dinamarqueses durante 1 hora de EF em três diferentes intensidades de esforço $(25,50$ e $75 \%$ do $\left.\mathrm{VO}_{2 \text { máx }}\right)$. Neste estudo, a linfocitose e posterior linfopenia foram observadas durante o EF a $50 \%$ e $75 \%$ do $\mathrm{VO}_{2 \operatorname{máx}}{ }^{93}$. Foi ainda verificado que a actividade citolítica de células NK e da linfocina activadora de células NK (LAK) aumentou durante todas as instâncias de esforço e foi suprimida 2 horas pós-esforço apenas a seguir o $\mathrm{EF}$ a $75 \%$ do $\mathrm{VO}_{2 \operatorname{máx}}{ }^{93}$.

De fato, a seguir 1 ou 2 horas de EF intenso de longa duração ( $>75 \%$ durante 1 hora), a concentração de células NK e a actividade citolítica diminuem em cerca de 25 - 40\% do nível basal 37,73 . E esta redução pode prolongar-se por até $2-4$ horas a seguir o EF72,73. Um estudo demonstrou que o EF exaustivo de força (sets de 10 repetições a $65 \%$ de 1 RM até a fadiga) em atletas treinados também provoca uma diminuição na função citolítica das células NK no período de recuperação (2 horas pósesforço) ${ }^{58}$. Da mesma forma, alguns pesquisadores observaram uma diminuição da actividade citolítica destas células em atletas remadores submetidos a um EF muito intenso de curta duração (6 minutos) ${ }^{55}$. Neste sentido, a intensidade, mais do que a duração, parece ser responsável pelo grau de incremento de células NK na circulação e pelas alterações funcionais destas células. Vale salientar que a diminuição da actividade citolítica das células NK no período de recuperação pode suscetibilizar o indivíduo a infecções 35 .

Durante um EF agudo ocorre também um aumento da concentração dos linfócitos $\mathrm{T}$, seguido de uma diminuição no período de recuperação ${ }^{76}$. Os linfócitos $\mathrm{T}$ podem ser divididos em sub-populações de acordo com as moléculas antigénicas de superfície co-receptoras: células $\mathrm{T}$ auxiliares $(\mathrm{CD} 4+)$ e células $\mathrm{T}$ citotóxicas ou supressoras $(\mathrm{CD} 8+)^{35}$. As células $\mathrm{T}$ $\mathrm{CD} 8+$, entre outras funções, são responsáveis pela destruição de células infectadas por vírus ou de células tumorais ${ }^{35}$. As células T CD4+ actuam na libertação de LAK, além de interferirem na estimulação, proliferação e maturação de linfócitos B 35 .

Um EF a $50 \%$ do $\mathrm{VO}_{2 \text { máx }}$ parece não alterar a concentração de células T CD4+ e T CD8+40,76,91,92. Um estudo não verificou modificação na percentagem de células T CD4+ e T CD8+ em 18 adultos jovens sedentários submetidos a cinco cargas repetidas de EF submáximo em cicloergómetro ${ }^{31}$. Contudo, alguns estudos tém observado que um EF a $75 \%$ do $\mathrm{VO}_{2 \text { máx }}$ tende a provocar uma diminuição na concentração de células T CD4+, sem alterar a concentração de células T CD8+3,25,76. Dessa forma, a proporção de $\mathrm{CD} 4+/ \mathrm{CD} 8+$ diminui refletindo um maior aumento de células $\mathrm{T} \mathrm{CD} 8+3$. E este aumento pode estar associado com estados de imunossupressão $0^{3,25,76}$.

Um linfócito activado deve proliferar antes que sua prole se diferencie em células efectoras para a produção de linfócitos específicos em número suficiente 
para combater uma infecção 76 . A duração e a intensidade do EF parecem ser determinantes na resposta proliferativa de linfócitos ${ }^{76}$. Em humanos, a resposta proliferativa de linfócitos $\mathrm{T}$ em resposta a um EF a $50 \%$ e $75 \%$ do $\mathrm{VO}_{2 \text { máx }}$ (durante 1 hora) parece diminuir no período de recuperação ${ }^{91,93}$. Contudo, durante e após um EF máximo de curta duração (6 minutos) não ocorreu alteração da resposta proliferativa de linfócitos ${ }^{55}$. Da mesma forma, não foi encontrado alteração na proliferação de linfócitos a seguir um EF de resistência de força ${ }^{58}$. Estes resultados decorrem, provavelmente, da presença de factores neuroendócrinos e de mediadores libertados por células imunes. A seguir exercícios intensos de longa duração (ex. ciclismo, natação, maratona) ocorre uma diminuição em cerca de $70 \%$ na concentração salivar da imunoglobulina A (IgA) por várias horas pós-esforço6,40. As Ig são glucoproteínas secretadas por linfócitos $\mathrm{B}^{76}$. Elas combinam-se especificamente com a substância que induziu sua produção e formam o braço humoral da resposta imune ${ }^{76}$. A IgA constitui 10 a $15 \%$ do total de imunoglobulinas, sendo a principal classe de anticorpo das mucosas ${ }^{6}$.

Alguns estudos relatam a não ocorrência de alterações na concentração salivar de IgA e de IgE, no soro, durante um exercício moderado $42,53,56,57$.

Contrariamente, Blannin et a ${ }^{6}$ encontraram baixas concentrações de IgA após uma corrida de $31 \mathrm{Km}$ a $65 \%$ do $\mathrm{VO}_{2 \text { máx. }}$. Outros estudos encontraram também uma diminuição na concentração de IgA, tanto na saliva quanto na mucosa nasal a seguir um EF intenso de longa duração $22,53,57$. Dessa forma, os pesquisadores estão a associar a coincidência desta redução com o aumento da prevalência de ITRS em atletas ${ }^{56,57}$. De fato, os estudos epidemiológicos relatam uma alta incidência de ITRS em maratonistas uma ou duas semanas a seguir uma prova ou um treinamento intenso $13,22,29,56$. Um estudo verificou que os sintomas de ITRS ocorridos em maratonistas foram na ordem de $33.3 \%$, enquanto os ocorridos no grupo controle foram de $15.3 \%{ }^{77}$. Embora os estudos revelem um aumento dos sintomas de ITRS a seguir um exercício intenso e de longa duração, não existem informações se esses sintomas são decorrentes do processo infeccioso em si, ou se são devidos a uma inflamação local ou sistémica causada pelo exercício ${ }^{76}$.
Muitos aspectos da relação existente entre exercício físico e imunidade ainda não estão totalmente esclarecidos. Factores como: o período de avaliação da alteração e da resposta imunológica, o nível de aptidão física e nutricional do indivíduo, o estado psicológico, o overtraining, as condições climáticas e os precedentes alérgicos e inflamatórios no trato respiratório, merecem ser considerados ${ }^{41}$. Ademais, a natureza transitória das alterações observadas pode, simplesmente, refletir uma automodulação das células imunes em busca da homeostase.

\section{EXERCÍCIO FÍSICO E A INTEGRAÇÃO ENTRE OS SISTEMAS NERVOSO, ENDÓCRINO E IMUNE.}

Durante e a seguir uma carga súbita de EF ocorrem alterações na concentração e na funcionalidade de células do SI ${ }^{76}$. Todavia, essas alterações não devem ser vistas isoladamente, mas como parte de uma complexa rede bidirecional de sistemas interligados 32,76 . Durante o exercício, é verificado um aumento nas concentrações de dopamina e noradrenalina a nível cerebral7. Em consequiência, há secreção da hormona libertadora da corticotropina (CRH) a nível hipotalâmico $^{7}$. A corticotropina (ACTH) e as b-endorfinas são então libertadas pela pituitária anterior ${ }^{7}$. A descarga de ACTH estimula o córtex adrenal a produzir glucocorticóides e aminas biogênicas ${ }^{7}$. De fato, a activação do SNS e os eventos seqüenciais do eixo HPA parecem possuir uma relação intrínseca com as componentes do SI, não só pela presença de receptores hormonais em leucócitos, mas também pela relação anatômica observada entre os três sistemas ${ }^{26,68}$. As células do SI parecem possuir receptores para as b-endorfinas, catecolaminas, cortisol, hormona do crescimento $(\mathrm{GH})$ e diversos outros mediadores envolvidos na reação ao stress $7,26,68$.

Em resposta tanto a um EF prolongado e intenso $\left(>70 \%\right.$ do $\left.\mathrm{VO}_{2 \max }\right)$ quanto a um exercício de curta duração e muito intenso ( $>85 \%$ do $\mathrm{VO}_{2 \max }$ ) ocorre um aumento das concentrações de b-endorfinas na circulação ${ }^{76,96}$. É interessante notar que os leucócitos expressam receptores para as $\beta$-endorfinas ${ }^{26}$. Esta constatação levanta a hipótese de uma possível influência desses mediadores na função de células do SI durante o exercício. Estudos com humanos sugerem que as b-endorfinas podem diminuir a produção de imunoglobulinas ${ }^{44,48}$. Recentemente foi verificado 
em ratos que as b-endorfinas inibem a proliferação de linfócitos e parecem estar envolvidas no aumento da quimiotaxia e da fagocitose de macrófagos peritoneais ${ }^{14,61}$. Da mesma forma, parece aumentar a actividade citolítica de células NK durante o stress crônico, mas não o recrutamento destas células para circulação ${ }^{76,96}$.

O recrutamento de PMN e das populações de linfócitos para o compartimento vascular durante o $\mathrm{EF}$ parece ser mediado pela adrenalina, e em menor grau pela noradrenalina ${ }^{69}$. Durante o EF, a adrenalina e a noradrenalina são libertadas da medula adrenal e a noradrenalina dos terminais nervosos simpáticos ${ }^{69,76}$. A concentração sanguínea desses mediadores aumenta linearmente com a duração do exercício e exponencialmente com a intensidade do mesmo ${ }^{76}$. A expressão de b-receptores nas diferentes células imunes fornece a base molecular para acção das catecolaminas $5,30,38$. Contudo, a densidade de receptores adrenérgicos e a eficiência do sistema de transdução AMPc diferem nos vários tipos de células imunocompetentes $5,26,68,94$. Os PMN e as células NK parecem apresentar maior número de receptores em comparação a outras células imunes ${ }^{26}$. Neste sentido, é provável que a resposta imediata destas células aos efeitos do EF agudo, moderado ou intenso, decorra do efeito modulador das catecolaminas ${ }^{90}$. Quando o exercício se prolonga, prossegue o aumento da concentração de PMN e linfócitos devido, provavelmente, a elevação das concentrações de cortisol no plasma ${ }^{69}$. O cortisol, em pequenas quantidades, melhora a função imune, visto que um dos papéis deste hormônio no SI é o de estimular a migração de células da medula para a circulação, assim como, dos linfonodos para os tecidos lesionados ${ }^{7}$.

Contudo, o aumento da concentração de cortisol no sangue pode causar linfocitopenia, monocitopenia e neutrofilia em humanos ${ }^{76}$. Esta hormona inibe a migração de células inflamatórias para locais lesionados, proliferação de linfócitos, e é inibidora da função de macrófagos e limitadora da actividade das células NK34,74,90,101 . Para além disso, parece induzir baixa na regulação de receptores de linfócitos $\mathrm{T}$ e aumentar a taxa de catabolismo, reduzindo as reservas de aminoácidos que são necessários para proliferação de linfócitos $\mathrm{B}$ e síntese de imunoglobulina ${ }^{51,54,71}$. Alguns estudos relatam ainda, que EF intenso de longa duração parece induzir a apoptose de linfócitos decorrente do aumento dos níveis de cortisol ${ }^{43}$. Portanto, os efeitos do aumento da concentração do cortisol podem estar relacionados à imunossupressão evidenciada após treinamentos exaustivos ou EF intensos e de longa duração. Ainda relacionado com a intensidade do esforço, a GH é também libertada da pituitária anterior durante o $\mathrm{EF}^{7}$. Nos mononucleares pode-se verificar receptores para a $\mathrm{GH}^{76}$. É interessante notar que em resposta ao stress físico, a GH quando combinada com a adrenalina provoca neutrofilia ${ }^{7}$. Contudo, parece não atuar no recrutamento de linfócitos para a circulação ${ }^{32}$.

As células imunocompetentes parecem, portanto, possuir não só receptores hormonais, mas também a capacidade para produzir e secretar algumas hormonas e neuropeptídeos ${ }^{26}$. De forma idêntica ao que acontece em células da pituitária, a produção destes peptídeos por células do SI respondem, na maioria dos casos, a factores inibitórios ou estimuladores do hipotálamo, bem como a hormonas envolvidas na regulação do feedback negativo 26,34 . Entretanto, a quantidade de hormonas e neuropeptídeos produzidos pelas células do SI é pequena, sugerindo que estas substâncias actuam de forma parácrina e autócrina ${ }^{16,34}$.

O braço recíproco da relação bidirecional entre os sistemas neuroendócrino e imune é constituído por mensageiros libertados das células imunes activadas, chamados citocinas ${ }^{17,47}$.

As citocinas são pequenas proteínas solúveis secretadas por leucócitos, e outras células, e que têm por função modular a resposta imune ${ }^{17}$. A resposta local para uma infecção ou tecido lesionado envolve a produção desses mediadores que vão facilitar o influxo dos vários tipos de leucócitos para a região atingi$\mathrm{da}^{26,47}$. Para além da sua acção mediadora no SI, as citocinas podem também actuar no SN e SE, modificando as suas funções26,17,47. Assim, o estímulo induz as células do SI a produzirem citocinas que, em resposta, parecem actuar nos três níveis: hipotalâmico, pituitário e adrenal 47 . De forma idêntica, os diferentes tipos de células do SN (neurónios, astrócitos e microgliócitos) também sintetizam citocinas e/ou respondem a elas ${ }^{26,47}$. A lista de citocinas é longa e inclui uma variedade de moléculas cuja origem, estrutura e função têm sido revisadas. 
De forma geral, o EF agudo intenso afecta a produção tecidual e sistêmica de citocinas, especificamente as interleucinas (IL) e o factor de necrose tumoral (TNF), assemelhando-se à resposta inflamatória a algum trauma ou infecção 47,67 .

Particularmente os EF excêntricos, os EF muito intensos de curta duração $\left(>100 \% \mathrm{VO}_{2 \text { máx }}\right)$ ou os intensos de longa duração $\left(>80 \% \mathrm{VO}_{2 \max }\right.$ por mais de $60 \mathrm{~min}$ ) provocam alterações metabólicas (redução da saturação da hemoglobina arterial e um aumento na temperatura corporal) e lesões musculares 1,11,19,24,66. A hipoxemia e as lesões teciduais associadas a estes tipos de exercício induzem a alterações na resposta imune com libertação de citocinas pró-inflamatórias incluindo a IL-1, a IL-6 e o TNF$a^{10,12,27,65,67}$. Entretanto, mais estudos são necessários para afirmar se essas alterações contribuem para imunomodulação relacionada ao exercício.

Neste sentido, a concentração plasmática de IL-1 parece aumentar significativamente em resposta tanto a um $\mathrm{EF}$ de longa duração a $60 \%$ do $\mathrm{VO}_{2 \text { máx }}$, quanto a um EF de curta duração a $75 \%$ do $\mathrm{VO}_{2 \text { máx }}{ }^{11,27}$. Da mesma forma, um estudo verificou um aumento de IL-1 a seguir um EF de resistência de força excêntrico (4x10 repetições a 100\% -1RM) ${ }^{87}$. A IL-1 é produzida em resposta à infecção nos tecidos periféricos por monócitos e macrófagos e no cérebro por microgliócitos e astrócitos ${ }^{47}$. É suposto que a IL1 opere como sinal aferente, estimulando o hipotálamo a libertar $\mathrm{CRH}^{5}$. A sua administração aumenta consideravelmente as concentrações de ACTH no plasma, constituindo-se como um importante estimulador do eixo HPA ${ }^{4,26}$. A IL-1 estimula a activação de linfócitos T e induz a proliferação de células ${ }^{47}$. Assim, o aumento da concentração desta citocina pode estar associado à resposta proliferativa de linfócitos $\mathrm{T}$ a seguir uma carga súbita de EF.

Outro potente mediador da resposta orgânica de fase aguda é a IL-647. Esta citocina é produzida por várias células imunes (linfócitos e monócitos) e por células não-imunes (condrócitos, astrócitos e células gliais) ${ }^{16}$. A sua administração aumenta a produção de ACTH pela pituitária, estimulando o córtex adrenal a libertar glucocorticóides ${ }^{26}$. A IL-6 funciona como um factor co-estimulador da activação de linfócitos $\mathrm{T}$ em resposta a um antigénio e é fundamental para maturação de linfócitos $\mathrm{B}^{2}$. De forma geral, o EF associado a lesões musculares induz um aumento transitório na concentração de IL-6 no plasma ${ }^{18,33}$. Um estudo observou um aumento de IL6 (29 vezes acima do valor basal) durante 2.5 horas de tapete ergométrico a $75 \%$ do $\mathrm{VO}_{2 \text { máx }} 88$. Em homens sedentários foi relatado um aumento dos níveis de IL-6 a seguir um EF a $75 \%$ do $\mathrm{VO}_{2 \text { máx }}$ por $60 \mathrm{~min}^{95}$. Moldoveanu et al ${ }^{46}$ verificaram um aumento desta citocina (18 vezes acima do valor basal) em jovens atletas submetidos a 3 horas de EF a $65 \%$ do $\mathrm{VO}_{2 \text { máx }}$. Outro estudo também verificou um aumento de IL-6 no plasma a seguir um EF de força excêntrico ( $100 \%$ de $1 \mathrm{RM}){ }^{87}$. A magnitude da resposta depende da intensidade, do tipo e da duração do esforço. Todavia parece não estar associada ao nível de aptidão física individual.

Muitos dos papéis fisiológicos do TNF-a assemelham-se àqueles da IL-1 e da IL-647. O TNF-a é produzido por linfócitos T, células de Kuppfer, células neurais e células endoteliais, contudo, os fagócitos mononucleares são os principais produtores de TNF$\mathrm{a}^{47}$. A presença desta citocina também está associada ao aumento nos níveis de ACTH no sangue ${ }^{16}$. O TNF-a induz a expressão de moléculas de adesão na superfície das células endoteliais, promovendo, assim, a migração de leucócitos para os locais de inflamação ${ }^{47}$. Apesar de existir alguma controvérsia devido ao período de avaliação dessa citocina no plasma, muitos investigadores encontraram um aumento de TNF-a a seguir $2-3$ horas de um EF intenso de longa duração (ex maratona, ciclismo) $8,19,52,64$. Um estudo verificou um aumento de TNF-a em resposta a 2 horas de ciclismo a $60 \%$ do $\mathrm{VO}_{2 \text { máx }} 8$. Outro estudo observou um aumento de $90 \%$ a seguir 3 horas de um EF aeróbico a $65 \%$ do $\mathrm{VO}_{2 \text { máx }}{ }^{46}$. Assim, a resposta desta citocina a um EF parece ser influenciada pela intensidade e duração do esforço. Todavia, mais estudos são necessários na avaliação do papel fisiológico do aumento da concentração de TNF-a em resposta a um EF.

Muitas áreas da imunologia do exercício ainda não estão totalmente elucidadas, incluindo o padrão da resposta imunológica do exercício agudo em outros tecidos que não o sangue; a integração entre o músculo esquelético e as células imunes; e, se, as mudanças neuroendócrinas são transitórias após freqüentes séries de EF agudo, ou se refletem adaptações hormonais persistentes que também estão presentes durante o repouso. 


\section{CONCLUSÕES}

Inúmeros estudos têm evidenciado alterações na concentração e na função de algumas componentes do SI provocadas pelo exercício físico. As evidências disponíveis demonstram que o EF tem efeitos modulatórios importantes sobre a dinâmica de células imunes e, possivelmente, sobre sua função.

Os factores neuroendócrinos que actuam na redistribuição de células e a libertação de citocinas em resposta ao exercício físico parecem mediar a relação entre o SI e o EF.

Apesar dos aspectos multifactoriais e das lacunas ainda existentes, essa nova área de investigação a "imunologia do desporto" vem se desenvolvendo nos últimos anos. O grande desafio dos investigadores, portanto, seria estabelecer um modelo baseado na intensidade, na duração, na freqüência e nos diferentes tipos de esforço físico de forma a instituir o binômio exercício/saúde.

\section{CORRESPONDÊNCIA}

\section{Dra. Célia M.M.B. de Castro}

LIKA - Departamento de Medicina Tropical - CCS

Universidade Federal de Pernambuco - UFPE

Campus Universitário s/n Cidade Universitária

Recife-Pernambuco

Brasil CEP 50670-901

ccastro@lika.ufpe

\section{REFERÊNCIAS BIBLIOGRÁFICAS}

1. Armstrong RB, Ogilive RW, Schwane JA (1983). Eccentric exercise-induced injury to rat skeletal muscle. J Appl Physiol 54 (1): 80-93

2. Baumann H, Gauldie J (1994). The acute phase response. Immunol Today 15: 74-80

3. Berk LS, Nieman DC, Tan SA (1989). Maximal exercise modifies lymphocytes and subpopulations $\mathrm{T}$ helper and $\mathrm{T}$ suppressor and ratio in man. Med Sci Sports Exercise 19:S43-S44

4. Besedovski HO, Del Rey A, Sorkin, E, Dinarello CA (1986). Immunoregulatory feedback between interleukina1 and glucocorticoid hormones. Science. 223, 625-654

5. Blalock JE (1994). The syntax of immune-neuroendocrine communication. Immunol Today 15: 504-511

6. Blannin, AK, Robson PJ, Walsh NP, Clark AM, Glennon L., Gleeson M. (1998). The effect of exercising to exhaustion at different intensities on saliva immunoglobulin A, protein and electrolyte secretion. Int J Sports Med. 19: 547-552

7. Brenner I, Shek PN, Zamecnik J, and Shephard RJ (1998). Stress Hormones and the immunological responses to heat and exercise. Int J Sports Med 10: 130-143

8. Brenner IK, Natale VM, Vasiliou P, Moldoveanu AI, Shek PN, Shephard RJ (1999). Impact of three different types of exercise on components of the inflammatory response. Eur J Appl Physiol Occup Physiol: 80(5):452-60

9. Brines R, Hoffman-Goetz L, and Pedersen BK (1996). Can you exercise to make your immune system fitter? Immunol Today 17: 252-254

10. Bruunsgard H, Galbo H, Halkjaer-Kristensen J, Johansen TL, Mac Lean DA, and Pedersen BK (1997). Exercise-induced increase interleukin- 6 is related to muscle damage. J Physiol 499: 833-841

11. Bury TB, Luis R, Radermaker MF. Pirnay F (1996). Blood mononuclear cells mobilization and cytokine secretion during prolonged exercises. Int J Sports Med 17: 156-160

12. Cannon JG, Fielding RA, Fiataroni MA, Orencole SF, Dinarello CA, Evans WJ (1989). Increased interleukin 1 beta in human skeletal muscle after exercise. Am J Physiol. 257: R451-R455

13. Cannon JG (1993). Exercise and resistance to infection. J Appl Physiol 74: 973-981.

14. Carlson SL, Brooks WH, Roszman TL (1989). Neurotransmitter-lynphocyte interactions: dual receptor modulation of lymphocyte proliferation and camp production. J Neuroimmunol. 24: 155-162

15. Davis JM, Kohut ML, Hertler-Colbert M, Jackson DA, Ghaffar A, Mayer EP (1997). Exercise, alveolar macrophage function, and susceptibility to respiratory infection. $J$ Appl Physiol 83:1461-1466

16. De Castro CB, Manhães-de-Castro R, Queirós A, Costa JA., Brandt CT (1999). Estresse: Interações neuroendócrinas e imunológicas. Anais Faculd de Med CCS - UFPE. 44 (2): $132-137$

17. De Castro CB., Manhães-de-Castro R, Medeiros AF, Queirós A, Ferreira WT, Lima Filho JL. (2000) Effect of stress on the production of $\mathrm{O}_{2}^{-}$in alveolar macrophages. $J$ Neuroimmunol. 108 (1) $68-72$

18. Drenth JPH, VanUun SHM, Van Deuren M, Pesman GJ, Van der Ven Jongekrug J, Van der Meer JW (1995). Endurance run increases circulating IL- 6 and IL-1ra but down regulates ex vivo TNF-a and IL-1b production. J Appl Physiol. 79: 1497-1503 
19. Dufaux B, Order U. (1989). Plasma elastase-al-antitrypsin, neopterin, tumor necrosis factor, and soluble interleukine-2-receptor after prolonged exercise. Int. J Sports Med. 10:434-438

20. Ferrandez MD, De la Fuente M (1999). Effects of age, sex and physical exercise on the phagocytic process of murine peritoneal macrophages. Acta Physiol Scand 166(1):47-53

21. Field CJ, Gougeon R, and Marliss EB. (1991). Circulating mononuclear cell numbers and function during intense exercise and recovery. J Appl Physiol 71: 1089-1097

22. Fitzgerald L. (1991). Overtraining increases the susceptibility to infection. Int J Sports Med 12: 55-58.

23. Forner A, Barriga C, and Ortega E, (1996). Exercise-induced stimulation of murine macrophage phagocytosis may be mediated by thyroxine. J Appl Physiol. 80:899-903

24. Fridén J. Sjostrom M, Ekblom B. (1983). Myofibrilar damage following intense eccentric exercise in man. Int. J. Sports Med 4: 170-176

25. Fry RW, Morton AR, Crawford GP, Keast D (1992). Cell numbers and in vitro responses of leukocytes and lymphocyte subpopulations following maximal exercise and interval training sessions of different intensities. Eur J Appl Physiol 64:218-227

26. Gaillard RC (1994). Neuroendocrine-Immune system interactions. The Immune-hypotalamo-pituitary-adrenal axis. Trends in Endoc Metabol (TEM) 7(5):303-309

27. Haahr PM, Pedersen BK, Fomsgaard A, Tvede N, Diamant M, Klarlund K, Halkjaer-Kristensen J, Bendtzen K (1991). Effect of physical exercise on in vitro production of interleukin 1 , interleukine 6 , tumor necrosis factor-a, interleukin 2 and interferon-g. Int J Sports Med. 12: 223-227.

28. Hack V, Strobel G, Rau JP, and Weicker H. (1992). The effect of maximal exercise on the activity of neutrophil granulocytes in highly trained athletes in a moderate training period. Eur J Appl Physiol 65: 520-524

29. Heath G W, Ford E.S; Craven T.E, Macera CA, Jackson K.L, Pate R.R. (1991). Exercise and the incidence of upper respiratory tract infections. Med Sci Sports Exercise 23: 152-157

30. Hellstrand K, Hermodsson S, Strannegard O. (1985). Evidence for beta-adrenorecpetor-mediated of human natural killer cells. Immunopharmacology. 134: 4095-4099

31. Hoffman-Goetz L, Simpson JR, Cipp N, Arumugam Y, and Houston ME. (1990). Lymphocyte subset responses to repeated submaximal exercise in men. J Appl Physiol 68: 1069-1074

32. Hoffman-Goetz L and Pedersen BK (1994). Exercise and the immune system: a model of the stress response? Imunol Today 15(8): 382-387

33. Jones, DA, Newnhan DJ, Round JM and Toifree SEJ (1986). Experimental human muscle damage: morphological changes in relation to other indices of damage. $\mathrm{Am} \mathrm{J}$ Physiol 375: 453-448.

34. Jonhson EO, Kamilaris TC, Chrousos GP, and Gold PW. (1992). Mechanism of stress: a dynamic overview of hormonal and behavioral homeostasis. Neurosci Biobehav Rev $16: 115-130$

35. Keast D, Cameron K, Morton AR. Exercise and the immune response (1988). Sports Med 5: 248-267

36. Kendall A, Hoffman-Goetz L., Houston M., MacNeil B, Arumugam Y. (1990). Exercise and blood lymphocyte subset responses: intensity, duration, and subject fitness effects. J. Appl. Physiol 69: 251-260
37. Klokker M, Kjaer M, Secher NH, Hanel B, Worm L, Kappel M, Pedersen BK (1995). Natural killer cell response to exercise in humans: effect of hypoxia and epidural anesthesia. J Appl Physiol 78: 709-716

38. Landmann R, Muller FB, Perini CH, Wesp M, Erne P, Buhler FR (1984). Changes of immune-regulatory cells induced by psychological and physical stress: relation to catecholamines. Clin Exp Immunol 58: 127-135

39. Macha M, Shlafer M, Kluger MJ (1990). Human neutrophil hydrogen peroxide generation following physical exercise. J Sports Med Phys Fitness 30:412-419

40. Mackinnon LT, Chick TW, Vanas A, Tomasi TB (1987). The effect of exercise on secretary and natural immunity. $A d v$ Exp Med Biol 216: 869-876

41. Mackinnon LT (1998). Future directions in exercise and immunology: regulation and integration. Int. J. Sports. Med.; 19: S205-S211

42. Mackinnon LT and Hooper S. (1994). Mucosal (secretory) immune system responses to exercise of varying intensity and during overtraining. Int J Sports Med 15 suppl: S179-S183

43. Mars M, Govender S, Weston A, Naicker V, and Chuturgoon A. (1998). High intensity exercise: a cause of lymphocyte apoptosis? Biochem Biophys Res Commun 19: 366-370

44. Mathews PM, Froelich CJ, Sibbit WL Jr, Bankhurst AD (1983). Enhancement of natural citotoxicity by betaendorphin. Immunopharmacology 1301658-1662.

45. McCarthy DA e Dale MM (1988). The leucocytosis of exercise. A review and model. Sports Med 6: 333-363.

46. Moldeveanu AI, Shephard RJ, Shek PN (2000). Prolonged exercise elevates plasma levels but not gene expression of IL-1b, IL-6, and TNF-a in circulation mononuclear cells. $J$ Appl Physiolo 89:1499-1504

47. Moldeveanu AI, Shephard RJ, Shek PN (2001). The cytokyne response to physical activity and training. Sports Med. 31 (2): 115-144

48. Morgan EL, McClurg MR, Janda JA (1990). Suppression of human B lymphocyte activation by beta-endorphin. $J$ Neuroimmunology 28: 209-217

49. Muns G (1994). Effect of long-distance running on polymorphonuclear neutrophil phagocytic function of the upper airways. Int J Sports Med 15(2):96-9

50. Muns G, Rubinstein I, Singer P (1996). Neutrophil chemotactic activity is increased in nasal secretions of long-distance runners. Int J Sports Med 17(1):56-9

51. Nascimento E, Manhães-de-Castro R, De Castro CB, Leandro CG (2001). Pode a glutamina modular a imunidade? Anais Faculd de Med CCS - UFPE. 46: 67-70

52. Nehlsen-Cannarella SL, Fagoaga OR, Nieman DC, Henson DA, Butterworth DE, Schmitt RL, Bailey EM, Warren BJ, Utter A, Davis JM. (1997). Carbohydrate and cytokine response to $2.5 \mathrm{~h}$ of running. J Appl Physiol. 82: 1662-1667

53. Nehlsen-Cannarella SL (1998). Cellular responses to moderate and heavy exercise. Can J. Physiol Pharmacol 76 (5): 485-489

54. Newsholme EA (1991). Biochemical mechanism to explain immunosuppression in well-trained and overtrained athletes. Int J Sports Med 15: (suppl 3): S142-S147

55. Nielsen HB, Secher NH, Kappel M, Hanel B, Pedersen BK (1996). Lymphocyte, NK and LAK cell responses to maximal exercise. Int J Sports Med 17: 60-65

56. Nieman D C, Johanssen LM, Lee JW, Arabatzis K. (1990a). Infections episodes in runners before and after the Los Angeles Marathon. J Sports Med Phys Fitness 30: 316-328 
57. Nieman DC, Nehlsen CSL, Markoff PA, Balk Lamberton AJ, Yang H Chritton DB, Lee JE Arabatzis K. (1990b). The effects of moderate exercise training on natural killer cells and acute upper respiratory tract infections. Int J Sports Med 11: 467-473

58. Nieman DC, Henson DA, Sampson CS, Herring JL, Suttles J, Conley M, Stone MH, Butterworth DE, Davis JM (1995). The acute immune response to exhaustive resistence exercise. Int J Sports med 16:322-328

59. Nieman DC. (2000). Is infection risk linked to exercise workload? Med Sci Sports Exerc 32(7):S406-411

60. Ortega E, Barriga C, De la Fuente M (1993). Study of the phagocytic function of neutrophils from sedentary men after acute moderate exercise. Eur J Appl Physiol 66:60-64

61. Ortega E, Forner MA, Barriga C (1996). Effect of betaendorphin on adherence, chemotaxis and phagocytosis of Candida Albicans by peritoneal macrophages. Comp Immunol Microbiol Infect Dis 19(4):267-74

62. Ortega E, Forner A, and Barriga C. (1997). Exercise-induced stimulation of murine macrophage chemotaxis: role of corticosterone and prolactine as mediators. J Physiol (Lond). 498:729-734

63. Ortega E, Forner MA, Garcia JJ, Rodriguez AB, Barriga C. (1999). Enhanced chemotaxis of macrophages by strenuous exercise in trained mice: thyroid hormones as possible mediators. Mol Cell Biochem 201(1-2):41-7

64. Ostrowski K, Hermann C, Bangash A, Schjerling P, Nielsen JN, and Pedersen BK. (1998a). A trauma-life elevation in plasma cytokines in humans in response to treadmill running. J Physiol (Lond) 508: 949-953

65. Ostrowski K, Rhode T, Zacho M, Asp S, Pedersen BK. (1998b). Evidence that IL-6 is produced in skeletal muscle during intense long-term muscle activity. J Physiol (Lond) 508: 904-906

66. Ostrowski K, Rhode T, Asp S. (1998c). The sequential release of cytokines in strenuous exercise. Int J Sports Med. 19:Suplpl. 3: S216-217

67. Ostrowski K, Rhode T, Asp S, Schjerling P, Pedersen BK. (1999). The cytokine balance and strenuous exercise: TNF-alpha, IL-2beta, IL-6, IL-1ra, sTNF-r2, and IL-10. J Physiol (Lond) 515: 287-291

68. Ottaviani E, Franceschi C (1996). The neuroimunology stress from invertebrates to man. Progr Neurobiol. 48: 421440

69. Ottaway CA and Husband AJ. (1994). The influence of neuroendocrine pathways on lymphocyte migration. Immunol Today 15: 511-517

70. Pannen BH and Robotham JL. (1995). The acute-phase response. Ne Horizons 3: 183-197

71. Parry-Bilings M, Budgett R, Koutedakis Y, Blomstrand E, Brooks S, Williams C, Calder P, Pilling S, Baigrie R, Newsholme EA. (1992). Plasma amino acid concentration in the overtaining system: possible effects on the immune system. Med Sci Sports Exercise 24: 1353-1358

72. Pedersen BK, Bruunsgaard H.(1995). How physical exercise influences the establishment of infections. Sports Med 19:193-400

73. Pedersen BK, Tvede N, Christensen LD, Klarlund K, Kragbak S, Halkjrkristensen J. (1989). Natural Killer cell activity in peripheral blood of highly trained and untrained persons. Int J Sports Med 10: 129-131
74. Pedersen BK, Kappel M, Klokker M, Nielsen HB, and Secher NH. (1994). The immune system during exposure to extreme physiologic conditions. Int J Sports Med 15 Suppl: S116-S121

75. Pedersen BK, Bruunsgaard H, Klokker M, Kappel M, MacLean DA, Nielsen HB, Rohde T, Ullum H, and Zacho M. (1997). Exercise-induced immunomodulation: possible roles of neuroendocrine factors and metabolic factors. Int $J$ Sports Med 18 Suppl: S2-S7

76. Pedersen KB e Hoffman-Goetz L. (2000). Exercise and the immune system: regulation, integration and adaptation. Physiol Rev 80 (3): 1055-1081

77. Peters EM and Bateman ED (1983) Ultra marathon running and upper respiratory tract infections: An epidemiological survey. South African Mel J 64, 582-584

78. Pyne DB (1994). Regulation of neutrophil function during exercise. Sports Med 17(4):245-58

79. Pyne DB, Baker MS, Smith JA, Telford RD, Weidemann MJ (1996). Exercise and the neutrophil oxidative burst: biological and experimental variability. Eur J Appl Physiol Occup Physiol 74(6):564-71

80. Pyne D.B e Gleeson M. (1998). Effects of intensive exercise training on immunity in athletes. Int J Sports Med 19: 138-194

81. Pyne DB, Smith JA, Baker MS, Telford RD, Weidemann MJ.(2000) Neutrophil oxidative activity is differentially affected by exercise intensity and type. J Sci Med Sport $3(1): 44-54$

82. Robson PJ, Blannin AK, Walsh NP, Castell LM, Gleeson M (1999). Effects of exercise intensity, duration and recovery on in vitro neutrophil function in male athletes. Int $J$ Sports Med 20: 128-135

83. Smith JA, Telford RD, Mason IB, and Weideman MJ. (1990). Exercise, training and neutrophil microbicial activity. In J Sports Med 11: 179-187

84. Smith LL. (1991). Acute inflammation: the underlying mechanism in delayed onset muscle soreness? Med Sci Sports Exercise 23: 542-551

85. Smith JA, Gray AB, Pyne DB, Baker MS, Telford RD, and Weideman MJ. (1996). Moderate exercise triggers both priming and activation of neutrophil subpopulations. Am J Physiol 270: R838-R845

86. Smith JA, Pyne DB (1997) Exercise, training, and neutrophil function. Exerc Immunol Rev;3:96-116

87. Smith LL, Anwar A, Fragen M, Rananto C, Johnson R, Holbert D (2000). Cytokines and cell adhesion molecules associated with high-intensity eccentric exercise. Eur J Appl Physiol : 82(1-2):61-7

88. Steensberg A, Toft AD, Schjerling P, Halkjaer-Kristensen J, Pedersen BK. (2001). Plasma interleukin-6 during strenuous exercise: role of epinephrine. Am J Physiol Cell Physiol 281(3):C1001-1004

89. Sternfeld B. (1992). Cancer and the protective effect of physical activity: the epidemiological evidence. Med Sci Sports Exerc. 24: 1195-1209

90. Tonnesen E, Christensen NJ, and Perdersen BK (1987). Natural Killer cell activity during cortisol and adrenaline infusion in healthy volunteers. Eur J Clin Invest 17: 497-503

91. Tvede N, Pedersen BK, Hansen FR, Bendix T, Christensen LD, Galbo H and Halkjaer-Kristensen J. (1989). Effect of physical exercise on blood mononuclear cell subpopulations and in vitro proliferative responses. Scand. J. Immunol 29: 383-389 
92. Tvede N, Steensberg J, Baslund B, Halkjaer-Kristensen J, and Pedersen BK (1991). Cellular immunity in highly trained elite racing cyclist during periods of training with high and low intensity. Scand J Med Sci Sports1: 163-166

93. Tvede N, Kappel M, Halkjaer-Kristensen J, Galbo H, and Pedersen BK. (1993). The effect of light, moderate and severe bicycle exercise on lymphocyte subsets, natural and lymphokine activated killer cells, lymphocyte proliferative response and interleukina-2 production. Int J Sports med 14: $275-282$

94. Tvede N, Kappel M, Krarlund K, Duhn S, Halkjaer-Kristensen J, Kjaer M, Galbo H, and Pedersen BK. (1994). Evidence that the effect of bicycle exercise on blood mononuclear cell proliferative response and subsets is mediated by epinephrine. Int J Sports med 15: 100-104

95. Ullum H, Haahr PM, Diamant M, Palmo J, HalkjaerKristensen J, and Pedersen BK. (1994). Bycicle exercise enhances plasma IL- 6 but does not change IL-1alpha, IL1beta, IL-6, or TNF-alpha pre m-RNA in BMNC. J Apll Physiol 77: 93-97

96. Van Den Bergh P, Rozing J, and Nagelkerken L. (1993). Identification of two moieties of beta-endorphin with opposing effects on rat T-cell proliferation. Immunology 79:18-23

97. Whiteside TL, and Herberman RB. (1989). The role of natural killer cells in human disease. Clin Immunol Immunophatol 53: 1-23

98. Woods JA, Davis JM, Mayer EP, Ghaffar A, Pate RR. (1993). Exercise increases inflammatory macrophage antitumor cytotoxicity. J Appl Physiol 75(2):879-86

99. Woods JA, Davis JM, Kohut ML, Mayer EP, Ghaffar A, and Pate RR. (1994). Effects of exercise on macrophage activation for antitumor cytotoxicity. J Appl Physiol 76: 2177-2185

100. Woods JA, Ceddia MA, Kozak C, Wolters BW (1997). Effects of exercise on the macrophage MHC II response to inflammation. Int J Sports Med 18(6):483-8

101. Woods JA (1999). Exercise and neuroendocrine modulation of macrophage function. Int J Sports Med 20 (5): 322-327

102. Woods JA, Davis JM, Smith JA, Nieman DC (1999). Exercise and cellular innate immune function. Med Sci Sports Exerc. 31(1): 57-76

103. Woods J, Lu Q Ceddia MA, Lowder T (2000). Special feature for the Olympics: effects of exercise on the immune system: exercise-induced modulation of macrophage function. Int J Sports Med 21 S1:S24-30 